\title{
PESQUISA DOS EDUCADORES E FORMAÇÃO DOCENTE VOLTADA PARA A TRANSFORMAÇÃO SOCIAL
}

\author{
KENNETH M. ZEICHNER \\ Departamento de Currículo e Ensino da Universidade do Estado de Wisconsin - EUA \\ zeichner@facstaff.wisc.edu
}

\section{JÚLIO EMÍLIO DINIZ-PEREIRA}

Faculdade de Educação da Universidade Federal de Minas Gerais

juliodiniz@fae.ufmg.br

\begin{abstract}
RESUMO
Este artigo procura desafiar algo que se tornou comum nos últimos anos: a glorificação acrítica da pesquisa-ação. Defende-se a idéia de que essa forma de investigação seja desenvolvida de maneira bastante séria e que sejam reforçados os laços do movimento de pesquisa-ação com as lutas mais amplas por justiça social, econômica e política. Argumenta-se que o movimento pode contribuir para o processo de transformação social em termos da sua capacidade de melhorar a formação profissional; do potencial controle que esses profissionais passam a exercer sobre o conhecimento que norteia o seu trabalho; da influência da pesquisa-ação sobre mudanças institucionais nos lugares em que esses profissionais trabalham; e, finalmente, da contribuição da pesquisa-ação para que as sociedades tornem-se mais democráticas e mais decentes para todos.

FORMAÇÃO DE PROFESSORES - PESQUISA EDUCACIONAL - MUDANÇA SOCIAL PESQUISA-AÇÃO
\end{abstract}

\section{ABSTRACT}

TEACHER RESEARCHAND TEACHER EDUCATION FOR SOCIAL TRANSFORMATION. This paper seeks to challenge the uncritical glorification of action research that has become common in recent years. It argues that we need to take action research much more seriously than is the case with its uncritical glorification. Thus, it defends the idea of linking the action research movement to the struggle for greater social, economic, and political justice. This paper discusses that the action research movement can contribute to the process of social transformation in terms of its ability to promote individual practitioner development; in terms 
of its potential effects on the control of the knowledge that informs the work of these practitioners; in terms of its influence on institutional change in the immediate settings in which these practitioners work; and finally, in terms of the impact of action research on the making of more democratic and decent societies.

TEACHER EDUCATION - EDUCATIONAL RESEARCH - SOCIAL CHANGE - ACTION RESEARCH

Embora um número crescente de pessoas perceba a cada dia o enorme potencial da pesquisa-ação e participe cada vez mais de comunidades que desenvolvem esse tipo de investigação, este artigo procura desafiar algo que se tornou comum nos últimos anos: a glorificação acrítica da pesquisa-ação.

Há aqueles que vêem a pesquisa-ação e o seu potencial para fomentar o trabalho dos profissionais como um fim em si mesmo, sem qualquer conexão com objetivos e lutas mais amplas na sociedade. Assume-se freqüentemente que os educadores, ao desenvolverem pesquisas sobre suas próprias práticas e, conseqüentemente, ao tornarem-se "mais reflexivos", necessariamente transformar-se-ão em melhores profissionais e que o conhecimento produzido por meio de suas investigações será necessariamente de grande importância, independentemente de sua natureza e qualidade. Essa visão ignora o fato de que maior autonomia e poder exercidos pelos educadores podem ajudar em alguns casos a solidificar e justificar práticas que são prejudiciais aos estudantes e à população de maneira geral. Isso acontece quando, por exemplo, os educadores adotam uma noção de profissionalismo que na verdade os afasta daqueles a quem estão servindo e de suas comunidades (Zeichner, 1991).

Essa glorificação acrítica do conhecimento gerado pela pesquisa-ação desrespeita a contribuição genuína que ela pode trazer para a melhoria da prática profissional e para o bem comum. Neste artigo, defendemos a idéia de que devemos tratar a pesquisa-ação de uma maneira muito mais séria do que acontece nesses casos e reforçar os laços do movimento de pesquisa-ação com as lutas mais amplas por justiça social, econômica e política em todo o mundo.

Discutiremos, então, neste texto, o modo pelo qual o movimento da pesquisa-ação, que continua a se expandir internacionalmente (Hollingsworth, 1997; McTaggart, 1997; Diniz-Pereira, Zeichner, 2002), pode contribuir para o processo de transformação social. Argumentamos que isso pode ocorrer de várias maneiras, tais como: I. melhorar a formação profissional e, por conseguinte, propiciar serviços sociais (educação, saúde etc.) de melhor qualidade; 2. potencializar o controle que esses profissionais passam a exercer sobre o 
Pesquisa dos educadores...

conhecimento ou a teoria que orienta os seus trabalhos; 3. influenciar as mudanças institucionais nos locais de trabalho desses profissionais (escolas, hospitais, agências de serviço social etc.); 4. contribuir para que as sociedades tornem-se mais democráticas e mais decentes para todos (ou seja, sua ligação com temas de reprodução ou de transformação social).

Adotamos neste artigo o termo "pesquisa-ação" com um significado bastante amplo: uma pesquisa sistemática feita por profissionais sobre as suas próprias práticas. Tem havido muita discussão na literatura especializada sobre o que é e o que não é a "verdadeira" pesquisa-ação; sobre os elementos da espiral de pesquisa-ação; sobre se ela deve ser colaborativa ou não; se deve ou não envolver facilitadores e avaliadores externos e assim por diante (ver, por exemplo, Elliot, 1991; Kemmis, McTaggart, 1988; McKernan, 1991; McNiff, 1988). Apesar de a discussão ser bastante informativa em termos acadêmicos, ela é essencialmente irrelevante para muitos daqueles que estão realmente envolvidos com a pesquisa-ação. Na opinião de Somekh:

Essa proliferação teórica sobre o que constitui pesquisa-ação serve para afastála da realidade das escolas e das salas de aula. $\bigcirc$ que isso tem a ver com professores ocupados para quem a validade de suas pesquisas baseia-se na capacidade que elas têm de responder as questões práticas sobre ensino e aprendizagem? (1989, p.5)

Existem diferentes culturas de pesquisa-ação e parece que uma enorme quantidade de tempo e energia é gasta para se discutir quem são os "verdadeiros" comprometidos com a pesquisa-ação e quem são os impostores.

Ainda que se reconheçam ganhos por parte do movimento, devemos olhar para ele como algo bastante dinâmico e heterogêneo. Cochran-Smith e Lytle (1998, 1999) alertam para o fato de que a pesquisa-ação tem sido implementada de maneiras muito distintas, refletindo diferentes compromissos políticos e ideológicos e diversas concepções sobre o aprendizado dos professores e dos estudantes.

\section{OS GANHOS DO MOVIMENTO DE PESQUISA-AÇÃO}

Nas décadas de 1980 e 1990, os termos pesquisa-ação, prática reflexiva e profissional reflexivo tornaram-se slogans para reformas educacionais ao 
redor do mundo. Por um lado, o movimento de pesquisa-ação significou um reconhecimento de que os profissionais produzem teorias que os ajudam a tomar decisões no contexto prático. Por outro lado, esse movimento internacional também pode ser entendido como uma reação contra a visão dos profissionais como meros técnicos que apenas fazem o que outros, fora da esfera da prática, desejam que eles façam e como uma rejeição às reformas "de cima para baixo" que concebem os profissionais apenas como participantes passivos.

Embora haja o risco de que esses sentimentos possam levar a uma rejeição passional do conhecimento gerado na universidade (e pensamos que esse seria um erro tão grande quanto a rejeição do conhecimento profissional), não podemos confiar apenas no conhecimento gerado na universidade para a formação profissional e melhoria institucional. Há muito o que aprender das teorias geradas na universidade, mas esse discurso externo deve ser de alguma forma integrado a um processo de pesquisa que é desenvolvido a partir da prática. Acreditamos que a participação dos profissionais e, mais especificamente, dos educadores, em projetos de pesquisa-ação, ou seja, o envolvimento direto deles com o processo de produção sistemática de um saber extremamente relevante e essencial para suas práticas, pode transformá-los também em "consumidores" mais críticos do conhecimento educacional gerado nas universidades. Isso pode acontecer porque esses sujeitos passariam a compreender melhor como tal conhecimento é produzido nos meios acadêmicos.

Da perspectiva do profissional isso significa que o processo de compreensão e melhoria de seu trabalho deve começar pela reflexão de sua própria experiência. Os slogans "reflexão" e "pesquisa-ação" também significam o reconhecimento de que o processo de aprendizagem de como se tornar um professor, um enfermeiro, um assistente social, continua por toda a carreira desses profissionais; um reconhecimento de que independentemente do que fazemos e de quão bem o fazemos em nossos programas de formação profissional, podemos no máximo formar profissionais para iniciarem suas práticas. Existe um compromisso de formadores de educadores e de formadores de outros profissionais de auxiliar futuros profissionais e iniciantes a internalizarem, durante sua formação inicial e nos primeiros anos de sua prática profissional, a disposição e a habilidade para investigar seu trabalho e de se aperfeiçoarem com o passar do tempo. Um compromisso de ajudar os profissionais a serem responsáveis por sua própria formação profissional. 
Pesquisa dos educadores...

\section{PESQUISA-AÇÃO E FORMAÇÃO PROFISSIONAL}

Passamos a discutir nesta seção se a pesquisa-ação tem realmente fomentado o desenvolvimento profissional. Apesar dos argumentos apresentados nas discussões acadêmicas da metade do século passado de que os professores seriam incapazes de desenvolver pesquisas ou de que esse tipo de atividade roubaria deles um tempo precioso a ser dedicado aos estudantes (veja, por exemplo, Hodgkinson, 1957), as evidências indicam fortemente que a pesquisa-ação tem sim auxiliado a formação de diferentes profissionais.

Desde as experiências pioneiras de John Eliott na Inglaterra, tem-se defendido a idéia da pesquisa dos educadores como uma das formas disponíveis e, talvez, uma das mais eficientes para a formação profissional. Geralmente se argumenta que os professores tornar-se-ão melhores naquilo que fazem por meio da condução de investigações sobre suas próprias práticas e que a qualidade da aprendizagem de seus alunos será melhor. Também se tem argumentado que a pesquisa dos educadores estimulará mudanças positivas na cultura e na produtividade das escolas, além de poder aumentar o status da profissão de magistério na sociedade.

Nos Estados Unidos infelizmente ainda predominam programas de formação profissional e de melhoria das escolas que ignoram o conhecimento e o saber dos professores e que se baseiam, essencialmente, na distribuição de pacotes e kits educacionais ou ainda em soluções para os problemas das escolas que geralmente não têm o menor respaldo empírico, e envolvem grandes custos para estas. A venda de soluções educacionais continua sendo um grande e rentável negócio nos EUA.

No Brasil, desde a implantação das reformas neoliberais em meados dos anos 80, a educação tem sido crescentemente, e de maneira similar ao que acontece nos Estados Unidos, concebida como um grande e promissor negócio. Há também muitas pessoas e instituições ganhando muito dinheiro com a venda de kits educacionais - muitas vezes rotulados como "construtivistas" ou o que estiver mais em moda no momento. A formação docente concentra-se em cursos de preparação inicial, geralmente baseados em modelos da racionalidade técnica e, quando existentes, os programas de formação continuada são normalmente centrados em cursos teóricos e de curta duração (ver DinizPereira, 1999; 2002). 
A literatura em educação é repleta de análises de experiências educacionais - programas de formação profissional que utilizam a pesquisa-ação - e de depoimentos pessoais de como os professores sentem que suas práticas de sala de aula, e em alguns casos de como suas vidas profissionais, têm sido transformadas por meio da pesquisa-ação.

Zeichner (2003), por exemplo, ao analisar quatro programas de pesquisa-ação desenvolvidos por professores do ensino fundamental dos Estados Unidos, conclui que, sob certas circunstâncias', a pesquisa dos professores parece promover aprendizagens específicas de professores e de alunos que muitos docentes consideram válidas e transformadoras. A experiência de se envolver em pesquisas do tipo "auto-estudo" (self-study research) ajuda ainda os professores a se tornarem mais confiantes em suas habilidades de ensinar, mais ativos e independentes ao lidarem com situações difíceis que surgem durante as aulas, assim como mais seguros ao adquirirem hábitos e habilidades de pesquisa que utilizam para analisar mais a fundo suas estratégias de ensino. A pesquisa dos professores parece também desenvolver neles motivação e entusiasmo em relação ao ensino, além de revalidar a importância de seu trabalho. Há ainda evidências da relação entre a pesquisa-ação e melhorias no aprendizado, comportamento e atitude dos estudantes. Os professores envolvidos na pesquisa de suas próprias práticas parecem ainda adotar modelos de ensino mais centrados nos alunos e se convecem da importância de ouvir, observar e procurar entender os alunos. Finalmente, os estudos de Zeichner levam-no a acreditar no poder da pesquisa dos professores para promover melhorias mais amplas nas escolas e nos sistemas de ensino do qual fazem parte.

I. $O$ autor assinala que certos contextos em que a pesquisa dos educadores se desenvolve podem fazer bastante diferença. Ele cita, por exemplo, como essencial o fato de os educadores-pesquisadores terem controle sobre diferentes aspectos do processo de pesquisa, incluindo a definição do foco de investigação, da coleta de dados e das estratégias de análise. Além disso, parece fundamental criar uma cultura de pesquisa que respeite as vozes dos educadores e o conhecimento que eles trazem para essa experiência de investigação. Outra condição importante para o sucesso da pesquisa-ação é o estabelecimento de um grupo de educadores-pesquisadores e de facilitadores externos trabalhando em ambiente seguro e colaborativo por um período de tempo substancial. Por fim, parece dispensável dizer que as condições estruturais são muitas vezes imprescindíveis: recursos fornecidos aos educadores para desenvolverem suas pesquisas (isto é, redução de carga horária didática, materiais de leitura e acesso a bibliotecas, apoio para publicação e apresentação de trabalhos) e oportunidades oferecidas aos educadores para encontrarem com os colegas de trabalho e discutirem com eles suas pesquisas. 
Pesquisa dos educadores...

As análises de depoimentos pessoais sobre como os professores investigadores de suas próprias práticas se sentem e avaliam sua participação em projetos de pesquisa-ação, afirmam que: a pesquisa-ação tem auxiliado no aumento da confiança e da auto-estima desses profissionais (Webb, 1990; Dadds, 1995; Loucks-Horsley et al., 1998); tem-Ihes ajudado a diminuir as distâncias entre as aspirações e as realizações na profissão (Elliot, Adelman, 1973; Elliot, 1980); tem sido um importante instrumento para os professores entenderem de maneira mais profunda e crítica a sua própria prática e para reverem suas teorias pessoais de ensino (Kemmis, 1985), tornando-os além de mais abertos e receptivos para novas idéias (Oja, Smulyan, 1989), mais independentes em relação à autoridade externa (Holly, 1990). Finalmente, a pesquisa-ação tem ajudado os professores a internalizarem a disposição para estudar as suas práticas de ensino (Day, 1984), alterando os discursos e as práticas desses profissionais, antes mais voltados aos "alunos problemáticos", para uma ênfase nos sucessos dos alunos e suas potencialidades (Atwell, 1987). Tais evidências levaram Grundy e Kemmis a concluir:

Os depoimentos de primeira mão dos professores e estudantes que estão envolvidos nesses projetos revelam que a pesquisa-ação tem freqüentemente sido a principal e mais importante experiência nas suas formações profissionais e pessoais e ainda que essa é uma experiência única em termos de transformação da prática. Em resumo, existe muita evidência na literatura especializada e nos depoimentos das pessoas que justifica a defesa da pesquisa-ação para a melhoria da formação profissional. (1988, p.33I)

Em gral, os professores que têm alguma experiência de pesquisa-ação concluem que está participando de algo que realmente Ihes interessa; algo que é realmente válido e relevante para eles.

Se esse sentimento de recompensa pessoal é acompanhado de uma melhoria da qualidade em termos de ensino e aprendizado, é um assunto mais complexo. Por um lado, alguns afirmam que a melhoria do ensino está associada ao fato de os professores investigarem a sua própria prática, mas que isso obviamente demanda tempo (veja, por exemplo, a experiência do "Ford Teaching Project" na Inglaterra; Elliot e Adelman, 1973; e as experiências estadunidenses de pesquisa-ação educacional relatadas por Cochran-Smith e Lytle, 1992). 
Há também evidências e relatos de que professores têm usado a pesquisa-ação para implementar de maneira mais eficiente práticas behavioristas de controle da sala de aula e outros modelos de ensino que não são nada parecidos com os descritos. Como afirma Ellwood ( 1992), a pesquisa-ação pode em alguns casos dar maior legitimidade a práticas educacionais que reforçam e fomentam iniqüidades sociais.

Em suma, é possível dizer que a pesquisa-ação está, sem sombra de dúvida, satisfazendo professores e ajudando-os a fazer o que desejam fazer de maneira melhor. Todavia, o que eles querem fazer é algo bastante diversificado que compreende desde práticas behavioristas, passando por práticas "construtivistas" (ou, em alguns casos, "neobehavioristas") até práticas mais críticas e politicamente orientadas. Para que as mudanças ocorridas nas práticas dos professores por meio da pesquisa-ação possam ser consideradas "melhorias", temos de analisar os méritos daquilo que se produz e se tais mudanças são válidas no contexto educacional de uma sociedade democrática.

Dessa maneira, apesar de todos os ganhos que o movimento dos educadores-pesquisadores tem tido nos últimos anos, uma grande quantidade de alunos não tem compartilhado das compensações geradas pelos esforços de melhoria da escola e da formação docente. E eles continuarão a não compartilhar esses benefícios até que exista uma preocupação mais explícita com a distribuição mais equânime dos resultados dessa melhoria.

\section{PESQUISA-AÇÃO E CONTROLE DO CONHECIMENTO}

Outra área em que o movimento de pesquisa-ação pode ser potencialmente catalisador de mudanças e em que ele tem dado uma contribuição significativa para a implementação é a do controle do conhecimento educacional que informa o trabalho dos profissionais.

Uma das características da pesquisa-ação educacional defendida por Lawrence Stenhouse, na Inglaterra na década de 70, era que, ao se fazer pública a pesquisa dos educadores, outros profissionais poderiam beneficiar-se dela; formadores de professores e pesquisadores nas universidades também poderiam incorporar o conhecimento produzido por meio da pesquisa-ação em cursos voltados para futuros professores ou para professores em treinamento; e, finalmente, gestores também poderiam usar tal conhecimento para desenvolver políticas educacionais (veja, por exemplo, Stenhouse, 1975). 
Pesquisa dos educadores...

Apesar de assistirmos a um crescimento contínuo das comunidades de pesquisa-ação por todo o mundo e mais especificamente das comunidades de educadores-pesquisadores e de suas publicações, ainda constatamos uma discriminação generalizada em relação ao tipo de conhecimento gerado pelos professores no âmbito da pesquisa educacional.

Apesar de os "guardiões" da pesquisa básica em educação terem se mostrado mais tolerantes com a pesquisa-ação, quando a questão é definir do que trata a "verdadeira" pesquisa educacional, a pesquisa-ação parece não ter relevância. Por exemplo, a maioria das universidades, que oferecem cursos de doutorado nos EUA, provavelmente não aceitaria um projeto de pesquisa-ação como tese. Existem também grupos de interesse específico na American Educational Research Association - Aera -, sobre pesquisa-ação e pesquisa dos professores, mas o status desses grupos e a sua importância na organização do encontro anual dessa associação é claramente marginal.

No Brasil, apesar de haver iniciativas de parcerias entre universidades e Secretarias de Educação para o desenvolvimento de programas de formação continuada que incluam a realização de pesquisas por parte dos professores, as condições de trabalho da maioria dos educadores são tão precárias que às vezes pode parecer piada de mau gosto falar em pesquisa desenvolvida por professores na escola. Com raríssimas exceções, a pesquisa educacional brasileira está, sem dúvida alguma, concentrada nas universidades. Por meio desses e de uma série de outros exemplos, é possível afirmar que a pesquisa-ação não tem conseguido alterar as relações de poder entre acadêmicos e profissionais quando a questão é definir o que realmente conta como pesquisa educacional.

Em publicação anterior, Zeichner (1995) defende a necessidade de suplantarmos a divisão entre a pesquisa dos educadores e a pesquisa acadêmica em educação. $\bigcirc$ autor sugere três estratégias principais para romper com essa separação: por meio do envolvimento dos profissionais das escolas em discussões sobre o significado e a importância das investigações desenvolvidas nas universidades e demais instiuições de pesquisa; por intermédio do desenvolvimento de projetos de pesquisa em colaboração com os professores nas escolas em que velhos modelos hierárquicos são realmente superados; e, finalmente, por meio do apoio a projetos de pesquisa-ação desenvolvidos pelos educadores, levando muito a sério o conhecimento produzido nesse processo. Zeichner lamenta o isolamento entre os professores nas escolas e os acadê- 
micos nas universidades e reafirma a necessidade da construção de alianças entre eles para a melhoria da educação e, mais especificamente, do ensino, e para a transformação social.

\section{PESQUISA-AÇÃO E TRANSFORMAÇÃO SOCIAL}

A terceira área na qual a pesquisa-ação educacional pode potencialmente ter um impacto transformador é a escola como instituição. Temos sido testemunhas da falta de sucesso da maioria, senão de todos os projetos que tentam mudar a escola "de cima para baixo", ignorando o conhecimento daqueles que nela trabalham. A pesquisa-ação tem o potencial de contribuir fundamentalmente para o refazer da escola como instituição, melhorando suas relações com a comunidade e promovendo uma educação de alta qualidade para todas as crianças, jovens e adultos. Por isso, defendemos a legitimidade e a importância de os professores e os formadores de professores controlarem suas próprias práticas em vez de os políticos, os profissionais de gestão escolar e educacional e os administradores externos fazerem isso.

Além da interferência, muitas vezes indesejada, desses sujeitos nas vidas e práticas dos educadores, tem sido bastante comum nos últimos anos criticar professores por suas visões muito estreitas sobre pesquisa-ação, por enfatizarem a compensação pessoal em detrimento da reconstrução social. Lawn (1989), Holly (1987), Nixon (1987) e Kemmis (1992) entre outros afirmam que a ênfase de professores-pesquisadores sobre a pesquisa-ação de sala de aula ignora as condições estruturais que moldam tais ações dentro do ambiente formal de ensino. A pesquisa-ação, que se assume ter o potencial para modificar as estruturas mais profundas da educação escolar, é criticada justamente por falhar em promover mudanças nas instituições escolares. Stephen Kemmis, por exemplo, conclui que:

A pesquisa-ação educacional tem sido capturada e domesticada em pesquisas de sala de aula individualistas, as quais falham em estabelecer pontes com forças políticas por reformas educacionais democráticas. (1985, p.5 I)

Um dos discursos subjacentes a esses argumentos é que existem coisas maiores e mais importantes acontecendo para além do limitado mundo da sala de aula e que todos podem vê-las; que se deve parar de desperdiçar o tempo 
Pesquisa dos educadores...

com questões triviais, como tentar melhorar o aprendizado dos estudantes. E se alguém quer realmente melhorar o aprendizado dos seus estudantes, que lute para mudar a instituição escolar, e as condições serão criadas para fazer essas melhorias possíveis.

Ainda que existam muitos méritos no argumento de se concentrar no contexto social e institucional em que a prática de ensino acontece, preocupanos a representação negativa que é freqüentemente associada aos professores que decidem manter as suas atenções na pesquisa de sala de aula. A maioria dos professores-pesquisadores continuará vinculada a investigações em salas de aula ou em grupos de salas de aula sem, necessariamente, se preocupar tanto com a instituição escolar ou a estrutura do trabalho docente. Pensamos que para incentivar ou apoiar a pesquisa-ação educacional ou escolar não é preciso atacar a pesquisa em sala de aula. Pensamos ainda que é bastante possível, dentro dos diferentes modelos de pesquisa-ação em sala de aula, estabelecer ligações com forças políticas que lutam por reformas democráticas como as sugeridas por Stephen Kemmis. Os professores não necessariamente precisam deixar a sala de aula para conectar as suas pesquisas com a luta por igualdade educacional e justiça social.

Se é verdade que o movimento de pesquisa-ação compartilha muitos dos compromissos políticos com aqueles que se identificam com a ciência social crítica em termos das lutas contra o status quo, essa associação com os teóricos críticos nas universidades pode excluir muitos nas comunidades de pesquisaação, por criar uma percepção de que "crítico" é algo que está longe e acima do mundo dos profissionais, em nível "macro", e as lutas em que os profissionais estão cotidianamente envolvidos no nível "micro" são, de alguma forma, pouco relevantes para uma dimensão mais ampla.

Há vários exemplos de situações em que grupos de professores desenvolvem projetos de pesquisa-ação em suas salas de aula cujos resultados ajudam a promover mudanças no nível institucional, tais como mudanças nas relações de poder da escola. Além disso, é possível afirmar que professores, ao desenvolverem suas investigações sobre temas relacionados especificamente à sala de aula, naturalmente levam em consideração o contexto institucional em que a sala de aula está localizada. Esses exemplos são pequenas vitórias que acontecem freqüentemente em comunidades de pesquisa-ação.

Allison Kelly ( 1985), referindo-se ao contexto britânico, lembra que essas pequenas vitórias podem ajudar professores a romper com o determinis- 
mo que diz: "As forças estruturais são muito maiores do que eu; não há nada que eu possa fazer" e, assim, evitar a desilusão que geralmente vem por não ter mudado o mundo todo de uma única vez. A pesquisa-ação pode ser uma ponte importante para os esforços mais amplos de reconstrução social. Deveríamos ser capazes de reconhecer a importância de cada pequena conquista ao longo desse caminho.

Assim, defendemos a idéia de que essas separações entre técnico e crítico, micro e macro são, na verdade, falsas dicotomias e de que a noção de "crítico" está na realidade incrustada no técnico e no mundo "micro" dos profissionais. Cada tema da sala de aula tem uma dimensão crítica. Indivíduos ou pequenos grupos de profissionais, tais como professores, podem não ser capazes de mudar estruturas sociais injustas por meio de pesquisas na sala de aula, mas esses professores podem ser bastante importantes e fazer a diferença em termos de como afetam a vida de seus estudantes. Embora seja verdade o fato de que apenas alguns professores e outros profissionais estão envolvidos em esforços que objetivam mais diretamente a transformação institucional e a ação nas comunidades, não deveríamos criticar os professores que se dedicam "apenas" aos limites de suas salas de aula. Como dissemos anteriormente, muitos professores continuarão preocupados com as suas salas de aula independentemente de o quanto são criticados por teóricos críticos nas universidades por fazerem "apenas" isso.

A realidade é que o político e o crítico estão em nossas salas de aula e em outros locais de trabalho, e as escolhas que fazemos diariamente em nossos ambientes de trabalho revelam nossos compromissos morais em relação à continuidade ou transformação social. Não podemos ser neutros. Conquanto não ignoraremos os esforços para mudar as estruturas para além da sala de aula, essa é um importante lugar para o que tem sido chamado de pesquisa-ação socialmente crítica ou uma pesquisa-ação que está conectada com a luta mais ampla por igualdade educacional e justiça social.

\section{PESQUISA-AÇÃO E LUTA POR JUSTIÇA SOCIAL}

Embora a pesquisa-ação tenha o potencial de fazer parte da construção de um mundo mais justo, não é sempre que se tem explorado esse potencial. Temos visto, por exemplo, no contexto da globalização hegemônica e da proliferação de políticas neoliberais ao redor do mundo, o crescimento das desi- 
Pesquisa dos educadores...

gualdades entre ricos e pobres em muitos países. Ainda que existam expectativas para associar a pesquisa-ação com a mitigação desses sofrimentos e injustiças dentro e para além da escola, e mesmo considerando as origens do movimento de pesquisa-ação antes da metade do século $X X$ nos Estados Unidos - vinculadas ao combate a preconceitos de raça e classe e ao trabalho ativo nas comunidades (Nofke, 1989; Altrichter, Gstettiner, 1997) -, freqüentemente não há, hoje, uma preocupação explícita com essas questões de igualdade educacional e de justiça social nas comunidades de pesquisa-ação.

Algumas pessoas criticam os apelos para que os pesquisadores de suas práticas intervenham no processo social, econômico e político em que estão inseridos. Pensamos, ao contrário, que seria um grande erro imaginar que poderíamos, de algum modo, ser participantes neutros em relação aos temas de reprodução ou de mudança social. Educadores de sociedades que se autodenominam democráticas têm a obrigação moral de intervir para que aqueles com quem trabalham possam viver mais plenamente os valores inerentes à democracia.

No contexto da globalização hegemônica e da proliferação de políticas neoliberais ao redor do mundo, temos testemunhado o crescimento do fosso que separa os ricos dos pobres. Raça, gênero, classe social, religião e opção sexual continuam a ser fatores importantes que na maioria das vezes determinam o acesso à educação de alta qualidade, assim como o acesso à boa moradia, à assistência médica de qualidade e a empregos que remunerem decentemente. Esses fatores continuam a influenciar um conjunto de outros problemas sociais, tais como a fome e a subnutrição, o abuso contra crianças, a gravidez indesejada na adolescência, crimes, violência e drogas.

Obviamente não estamos sugerindo que esses e outros problemas tenham sido causados pela "ineficiência" da escola pública, argumento empregado com freqüência na retórica de muitos políticos e gestores educacionais. As escolas públicas não causam tais problemas, e a sua reforma por si só também não poderá resolvê-los. O que sugerimos é que precisamos desempenhar um papel politicamente consciente em qualquer esfera que se escolha trabalhar, que examinemos as implicações sociais e políticas das nossas ações e, finalmente, que atuemos de modo a promover os valores democráticos.

Para aqueles que estão envolvidos em projetos de pesquisa-ação isso significa que toda e qualquer pesquisa-ação deve considerar, em algum ponto do desenvolvimento da investigação, as implicações sociais e políticas de suas 
práticas. Também significa que é preciso haver preocupação pública entre os pesquisadores quanto ao que se pode fazer como educadores e como seres humanos para minimizar a dor e o sofrimento dos que estão ao redor.

Gaby Weiner (1989) analisa, por exemplo, dois segmentos distintos do movimento de pesquisa dos educadores no Reino Unido: o que ela chama de "movimento dominante" e de "movimento de gênero". Segundo essa autora, as pesquisadoras feministas colocaram mais ênfase sobre os resultados da pesquisa-ação e se comprometeram com o estabelecimento da justiça social na formação profissional. Os dois grupos de investigadores, de acordo com Weiner, estavam preocupados com a emancipação e a maior autonomia dos professores, com a criação de condições em que os professores, e não os acadêmicos e pesquisadores externos, pudessem desenvolver uma teoria educacional enraizada em suas práticas de sala de aula; todavia, apenas as pesquisadoras feministas procuraram explicitamente conectar os seus esforços com questões de eqüidade e justiça social. A autora expressou ao final de seu artigo a esperança de que no futuro a pesquisa dos educadores pudesse abranger o duplo objetivo de melhoria do autoconhecimento (self-knowledge) e de promoção da justiça social.

Pensamos que Weiler estava correta quando defendeu em seu artigo, no final dos anos 80, a idéia da pesquisa-ação voltada tanto para a compensação pessoal quanto para a reconstrução social. Se por um lado sabemos da existência de professores que têm atuado sobre as implicações sociais e políticas de suas práticas quando desenvolvem projetos de pesquisa-ação em suas escolas e salas de aula, por outro, existem vários exemplos de professores ou de grupos de professores que têm associado suas pesquisas ao duplo objetivo de compensação pessoal e reconstrução social.

\section{CONSIDERAÇÕES FINAIS}

Gostaríamos de concluir chamando a atenção da comunidade internacional de profissionais envolvidos em pesquisa-ação para que conectemos nossas investigações ou nossos trabalhos como facilitadores de pesquisa-ação com o duplo objetivo de compensação pessoal e reconstrução social. Do contrário, corremos o risco de reforçarmos uma segmentação que atualmente já nos divide. 
Pesquisa dos educadores...

Por um lado, temos a glorificação da compensação pessoal como um fim em si mesma e que nega a responsabilidade social. Por outro lado, existem aqueles que defendem mais vigorosamente a exploração das implicações sociais e políticas da pesquisa-ação de sala de aula e que esta deveria ser desenvolvida de maneira a enfatizar a investigação nas escolas e nas comunidades ao seu redor, para confrontar as políticas e estruturas institucionais. Defende-se ainda um tipo de pesquisa-ação que diretamente desafie os "guardiões" do que é considerado a "verdadeira" pesquisa educacional. Claro que essas ênfases devem ser apoiadas, mas não em detrimento da pesquisa-ação de sala de aula e tão pouco da negação da importância do conhecimento acadêmico.

Embora sejamos comprometidos com os valores e os princípios associados à pesquisa-ação (ou seja, democratizar o processo de pesquisa e amplificar a voz dos profissionais na definição do curso de políticas que afetam o seu trabalho cotidiano), estamos também empenhados em associar pesquisa-ação a temas mais amplos como, por exemplo, o de tornar as sociedades mais humanas e solidárias. Enfatizamos, desse modo, a necessidade da pesquisa-ação ir além da retórica de se "dar voz aos profissionais" para a definição e melhoria de seu próprio trabalho. Mesmo concordando que o fato de se "dar voz aos profissionais" também seja algo importante, sabemos que isso não é suficiente.

Precisamos também reforçar nossos laços com os movimentos sociais de massa que trabalham para a promoção da justiça social, econômica e política no planeta. Embora a pesquisa-ação possa contribuir apenas com uma pequena parte dessas lutas, ela é parte importante. Assim, como pertencentes a uma comunidade de pesquisa-ação, precisamos ter a consciência pública e social mais ampla, explicitando nossos compromissos com as lutas por um mundo em que todos tenham acesso a vidas dignas e decentes.

\section{REFERÊNCIAS BIBLIOGRÁFICAS}

ALTRICHTER, H.; GSTETTINER, P. Action research: a closed chapter in the history of German social science? In: McTAGGART, R. (org.) Participatory action research : contexts and consequences. Albany: Suny, 1997.

ATWELL, N. Class-based writing research: teachers learning from students. In: GOSWAMI, D.; STILLMAN, P. (orgs.) Reclaiming the classroom: teacher research as an agency for change. Portsmouth: Heinemann, 1987. p.87-94. 
COCHRAN-SMITH, M.; LYTLE, S. Communities for teacher research: fringe or forefront. American Journal of Education, v. 100, n.3, p.298-324, 1992.

Teacher research: the question that persists. International Journal of Leadership in Education, n. I, p. 19-36, 1998.

The Teacher research movement: a decade later. Educational Research, v.28, n.7, p. I5-25, 1999.

DADDS, M. Passionate inquiry and school development. London: Falmer, 1995.

DAY, C. Teachers' thinking, intentions and practice: an action research perspective. In: HALKES, R.; OLSON, J. (orgs.) Teacher thinking. Lisse: Swets \& Zeitlinger, 1984. p.73-83.

DINIZ-PEREIRA, J. E. As Licenciaturas e as novas políticas educacionais para formação docente. Educação \& Sociedade, n.68, p. 109-125, 1999.

A Pesquisa dos educadores como estratégia para construção de modelos críticos de formação docente. In: DINIZ-PEREIRA, J. E.; ZEICHNER, K. M. (orgs.) A Pesquisa na formação e no trabalho docente. Belo Horizonte: Autêntica, 2002. p. I I-42.

DINIZ-PEREIRA, J. E.; ZEICHNER, K. M. (orgs.) A Pesquisa na formação e no trabalho docente. Belo Horizonte: Autêntica, 2002.

ELLIOT, J. Action research for educational change. Milton Keynes: Open University Press, 1991.

Implications of classroom research for professional development. In: HOYLE, E.; MEGARRY, J. (orgs.) Professional development of teachers. London: Kogan Page, 1980. p.308-324.

ELLIOT, J.; ADELMAN, C. Reflecting where the action is: the design of the Ford Teaching Project. Education for Teaching, v.9, n.2, p.8-20, 1973.

ELLWOOD, C. Teacher research: for whom? In: REUNIÃO ANUAL DA AERA, San Francisco, 1992. mimeo.

GRUNDY, S.; KEMMIS, S. Educational action research in Australia: the state of the art (an overview). In: KEMMIS, S.; McTAGGART, R. (orgs.) The Action research reader. 3.ed. Geelong: Deakin University Press, 1988, p.321-335.

HODGKINSON, H. Action research: a critique. Journal of Educational Sociology, v. 3 I , n.4, p.|37-153, 1957.

HOLLINGSWORTH, S. (org.). International action research: a casebook for educational reform. Washington: Falmer, 1997. 
Pesquisa dos educadores...

HOLLY, M. L. Teachers' theorizing: research and professional growth. In: REUNIÃO ANUAL DA AERA, Boston, 1990. mimeo.

HOLLY, P. Action research cul-de-sac or turnpike. Peabody Journal of Education, v.64, n.3, p.7I-99, 1987.

KELLY, A. Action research: what is it and what can it do? In: BURGESS, R. (org.). Issues in educational research: qualitative methods. Lewes: Falmer, |985. p. |29-|5|

KEMMIS, S. Action research. In: HUSEN, T.; POSTLETHWAITE, T. (orgs.) International encyclopedia of education: research and studies. Oxford: Pergamon, 1985. p.35-42.

The Nature of action research: some general principles. Leioa: Universidad del País Vasco, 1992. (Série de palestras no Instituto de Ciencias de la Educación.)

KEMMIS, S.; McTAGGART, R. The Action research planner. Geelong: Deakin University Press, 1988.

LAWN, M. Being caught in schoolwork: the possibilities of research in teachers' work. In: CARR, W. (org.) Quality in teaching. Lewes: Falmer, 1989. p. |47-161.

LOUCKS-HORSLEY, S. et al. Designing professional development for teachers of Science and Mathematics. Thousand Oaks: Corwin, 1998.

McKERNAN, J. Curriculum action research. London: Kogan, |99|.

McNIFF, J. Action research: principles and practice. London: Macmillan, 1988.

McTAGGART, R. (org.). Participatory action research: international contexts and conseqüences. Albany: Suny, 1997.

NIXON, J. The Teacher as researcher: contradictions and continuities. Peabody Journal of Education, v.62, n.2, p.20-32, 1987.

NOFKE, S. Action research: a multidimensional analysis. Madison, 1989. (PhD) Thesis. University of Wisconsin.

OJA, S.; SMULYAN, L. Collaborative action research: a developmental approach. London: Falmer, 1989.

SOMEKH, B. The Role of action research in collaborative enquiry. In: SOMEKH, B.; POWNEY, J.; BURGE, C. (orgs.) Collaborative enquiry and social improvement. Noewich: Classroom Action Research Network, University of East Anglia, 1989. p.3-II.

STENHOUSE, L. An introduction to curriculum research and development. London: Helnemann, 1975.

WEBB, R. Practitioner research in the primary school. Lewes: Falmer, 1990. 
WEINER, G. Professional self-knowledge versus social justice: a critical analysis of the teacher research movement. British Educational Research Journal, n. I5, p.4I-5I, 1989.

ZEICHNER, K. M. Beyond the divide of teacher research and academic research. Teachers and Teaching: Theory and Practice, v. I, n.2, p. I53-172, 1995.

.Contradictions and tensions in the professionalization of teaching and the democratization of the schools. Teachers' College Record, n.92, p.363-379, 199 I.

Teacher research as professional development for $\mathrm{P}-12$ educators in the USA. Educational Action Research, v. I I, n.2, p.30I-325, 2003.

Recebido em: janeiro 2005

Aprovado para publicação em: fevereiro 2005 